\title{
Heat Treatment Improves UV Photoprotective Effects of Licorice in Human Dermal Fibroblasts
}

\author{
Jeong-Yong Park ${ }^{1,2}$, Yun-Jeong Ji ${ }^{2}{ }^{\mathbb{D}}$, Kyung Hye Seo ${ }^{3}$, Ji Yeon Lee ${ }^{4} \mathbb{D}$, Geum-Soog Kim ${ }^{2}$, Min Hye Kang ${ }^{2}$, \\ Jeong Hoon Lee ${ }^{2}$, Gwi Yeong Jang ${ }^{2, *}$ and Hyung Don Kim ${ }^{2,5, * \mathbb{D}}$
}

1 Department of Medicinal Plant Resources, Andong National University, Andong 36729, Korea; yong0433@cbnu.ac.kr

2 Department of Herbal Crop Research, NIHHS, RDA, Eumsung 27709, Korea; jyj2842@korea.kr (Y.-J.J.); kimgs0725@korea.kr (G.-S.K.); mohak2@korea.kr (M.H.K.); artemisia@korea.kr (J.H.L.)

3 Development of Horticultural Crop Research, NIHHS, RDA, Jeonju 55365, Korea; seokh@korea.kr

4 MEDIOGEN, Co., Ltd., Jecheon 27159, Korea; ljy341@naver.com

5 Department of Biochemistry, School of Life Sciences, Chungbuk National University, Cheongju 28644, Korea

* Correspondence: janggy@korea.kr (G.Y.J.); khd0303@rda.go.kr (H.D.K.)

Citation: Park, J.-Y.; Ji, Y.-J.; Seo, K.H.; Lee, J.Y.; Kim, G.-S.; Kang, M.H.; Lee, J.H.; Jang, G.Y.; Kim, H.D. Heat Treatment Improves UV Photoprotective Effects of Licorice in Human Dermal Fibroblasts. Processes 2021, 9, 1040. https://doi.org/ $10.3390 /$ pr9061040

Academic Editor: Bing-Huei Chen

Received: 8 May 2021

Accepted: 10 June 2021

Published: 15 June 2021

Publisher's Note: MDPI stays neutral with regard to jurisdictional claims in published maps and institutional affiliations.

Copyright: (c) 2021 by the authors. Licensee MDPI, Basel, Switzerland. This article is an open access article distributed under the terms and conditions of the Creative Commons Attribution (CC BY) license (https:// creativecommons.org/licenses/by/ $4.0 /)$.

\begin{abstract}
External stimulation of the skin by ultraviolet B (UVB) radiation induces oxidative stress or inflammation, causing skin aging and skin cancer. Glycyrrhiza uralensis (licorice) has been used as a medicinal plant for its antioxidant, anti-inflammatory, antiviral, antimicrobial, anticarcinogenic, and hepatoprotective properties. The present study analyzed the effects of thermal processing on the bioactivities of licorice. Heat-treated licorice (HL) extracts had better antioxidant and antiinflammatory activities than non-treated licorice (NL) extract. HL extracts also had higher total phenol contents than NL extract. In particular, contents of isoliquiritigenin, an antioxidant and anti-inflammatory substance of licorice, increased in proportion to the skin-protection effects of HL extracts. Heat treatment increased the contents of phenolic compounds such as isoliquiritigenin in licorice extract, which improved the UV photoprotective effect of licorice in human dermal fibroblasts.
\end{abstract}

Keywords: Glycyrrhiza uralensis; reactive oxygen species (ROS); NF-кB; inflammation; isoliquiritigenin

\section{Introduction}

Ultraviolet (UV) radiation is subdivided into several main types based on wavelength, including ultraviolet A (UVA), ultraviolet B (UVB), and ultraviolet C (UVC) (100-400 nm). UVC and UVB radiation are completely or mostly absorbed, respectively, by the ozone layer in the atmosphere [1]. As the ozone layer is being depleted due to environmental pollution, UVB is increasingly reaching Earth's surface [2]. Exposure to UVB leads to DNA damage, pigmentation, and inflammatory diseases, and excessive exposure can lead to skin cancer [3,4]. Exposure to UVB also indirectly induces oxidative DNA damage through the generation of reactive oxygen species (ROS) [5]. Inflammation-related pathways in the skin, such as the nuclear factor kappa B (NF- $\mathrm{kB}$ ) pathway, are activated by ROS [6]. Activated NF- $\mathrm{kB}$ in the cytoplasm migrates into the nucleus, activating inducible nitric oxide synthase (iNOS), cyclooxygenase-2 (COX-2), and proinflammatory cytokines such as interleukin (IL)-6 and IL-1 $\beta$ [7].

Glycyrrhiza uralensis Fischer (licorice) is a perennial shrub of the Leguminosae family, growing mainly in China, Japan, the USA, and Europe. Licorice has been used as a nutritious sweetener in food since ancient times [8]. Dried roots and stems of licorice are also used for medicinal purposes [9]. Many studies have reported that licorice has antioxidant, anti-inflammatory, antiviral, antimicrobial, anticarcinogenic, and hepatoprotective activities [10-12]. The protective effect of licorice against UVB in HaCaT cells has also been reported [13]. Licorice contains natural bioactive components such as triterpenes (glycyrrhetic acid and glycyrrhizin) and phenols (liquiritin, liquiritigenin, isoliquiritin, and 
isoliquiritigenin) [14,15]. Isoliquiritigenin has known anti-inflammatory, immunomodulatory, anticancer, and antiapoptotic properties [16-18]. A previous study found that many chemical compounds in licorice, such as glycyrrhizin and isoliquiritigenin, were altered after heat treatment [19-21].

Thermal processes are commonly used for preservation and are known to alter the physicochemical and biological properties of plants [22]. During heat treatment, antioxidant activity increases as bioactive substances are synthesized from insoluble components of plants [23]. However, excessive heat can reduce the antioxidant capacity and bioactivity via the loss of nutrients, phenolic compounds, and carotenoids [24]. The appropriate temperature and time for heat treatment can lead to beneficial changes in the components of plants [25]. Previous studies have reported that thermal processes increase phenolic compounds [26] and improve antimutagenic activity and antimicrobial effects [27]. The aim of this study was to confirm the effects of thermal processes on the UV photoprotective activity of licorice in dermal fibroblasts and determine the components related to the activity.

\section{Materials and Methods}

\subsection{Sample Preparation}

The licorice (NL) used in this study was cultivated in Jecheon, Korea, in 2018, and dried at $60^{\circ} \mathrm{C}$ for $20 \mathrm{~h}$. Dried licorice $(5 \mathrm{~g})$ was placed in a glass container with $1 \mathrm{~mL}$ distilled water and treated in an autoclave (Jisico, Seoul, Korea) for $1 \mathrm{~h}$ at $120^{\circ} \mathrm{C}$ or $130^{\circ} \mathrm{C}$ (HL-1 and HL-2, respectively). NL and HL were extracted using 70\% ethanol (sample:solvent, $1: 50, v: v)$ for $24 \mathrm{~h}$ at room temperature (RT). After filtration, all extracts were evaporated in vacuo, freeze-dried, and stored at $-80^{\circ} \mathrm{C}$. All extracts were dissolved in DMSO (Sigma, St. Louis, MO, USA) for use in each experiment.

\subsection{2,2-Diphenyl-1-picrylhydrazyl (DPPH) Scavenging Activity}

DPPH scavenging activity was measured according to the Mishra et al. method, with some modifications [28]. DPPH solution in 95\% ethanol was prepared. Next, $50 \mu \mathrm{L}$ of sample and $200 \mu \mathrm{L}$ of DPPH solution were mixed, covered with aluminum foil, and incubated for $30 \mathrm{~min}$ at RT. Absorbance was measured using a microplate reader (BioTek, Winooski, VT, USA) at $515 \mathrm{~nm}$. The results were calculated according to the following equation, with each value as the half-maximal inhibitory concentration $\left(\mathrm{IC}_{50}\right)$ :

$$
\begin{gathered}
\text { DPPH radical scavenging activity }(\%)= \\
{\left[\left\{\left(\mathrm{A}_{\text {Control }}-\mathrm{A}_{\text {Blankl }}\right)-\left(\mathrm{A}_{\text {Treatment }}-\mathrm{A}_{\text {Blank } 2}\right)\right\} / \mathrm{A}_{\text {Control }}-\mathrm{A}_{\text {Blank1 } 1}\right] \times 100}
\end{gathered}
$$

where $\mathrm{A}_{\text {Treatment }}=$ absorbance value of DPPH with sample treatment; $\mathrm{A}_{\mathrm{Blank} 1}=$ absorbance value of ethanol with DMSO; $\mathrm{A}_{\mathrm{Blank2}}=$ absorbance value of ethanol with sample treatment; $\mathrm{A}_{\text {Control }}=$ absorbance value of DPPH with DMSO.

\subsection{ABTS $^{+}$Scavenging Activity}

$\mathrm{ABTS}^{+}$scavenging activity was measured as described by Lee et al., with some modification [29]. $\mathrm{ABTS}^{+}$solutions in distilled water were prepared and incubated for $24 \mathrm{~h}$. Next, $20 \mu \mathrm{L}$ of sample and $180 \mu \mathrm{L}$ of $\mathrm{ABTS}^{+}$solution were mixed, covered with aluminum foil, and incubated for $30 \mathrm{~min}$ at RT. Absorbance was measured using the microplate reader at $732 \mathrm{~nm}$. The results were calculated according to the following equation, with each value as the $\mathrm{IC}_{50}$ :

$$
\begin{gathered}
\text { ABTS }^{+} \text {scavenging activity }(\%)= \\
{\left[\left\{\left(\mathrm{A}_{\text {Control }}-\mathrm{A}_{\text {Blankl }}\right)-\left(\mathrm{A}_{\text {Treatment }}-\mathrm{A}_{\text {Blank }}\right)\right\} / \mathrm{A}_{\text {Control }}-\mathrm{A}_{\text {Blank1 } 1}\right] \times 100}
\end{gathered}
$$

where $\mathrm{A}_{\text {Treatment }}=$ absorbance value of $\mathrm{ABTS}^{+}$with sample treatment; $\mathrm{A}_{\mathrm{Blank} 1}=$ absorbance value of water with DMSO; $\mathrm{A}_{\mathrm{Blank2}}=$ absorbance value of water with sample treatment; $\mathrm{A}_{\text {Control }}=$ absorbance value of $\mathrm{ABTS}^{+}$with DMSO. 


\subsection{Cell Culture and UVB Treatment}

Human dermal fibroblasts (HDFs) (ATCC, Manassas, VA, USA) were grown in DMEM supplemented with $10 \%$ FBS and 1\% $p / s$ (Gibco, Grand Island, NY, USA) in a humidified $5 \% \mathrm{CO}_{2}$ atmosphere at $37^{\circ} \mathrm{C}$. The cells were washed with PBS (Gibco) and exposed to $100 \mathrm{~mJ} / \mathrm{cm}^{2}$ UVB irradiation using a Spectrolinker (XL-1000, Spectronics, Westbury, NY, USA) without the culture plate cover. Then, the UVB-exposed cells were immediately placed in a serum-free medium containing licorice extract for $24 \mathrm{~h}$.

\subsection{Cell Viability}

The effects of HL extracts on the viability of UVB-exposed HDFs were investigated using a CellTiter 96 AQueous One Solution Cell Proliferation Assay (MTS) kit (Promega, Madison, WI, USA). HDFs were seeded into 96-well culture plates at a density of $5 \times 10^{4}$ cells/well for $24 \mathrm{~h}$. Cells were treated with licorice extracts at various concentrations $(25-200 \mu \mathrm{g} / \mathrm{mL})$ and incubated at $37^{\circ} \mathrm{C}$ for $24 \mathrm{~h}$. Then, MTS was added and the absorbance was measured using the microplate reader at $490 \mathrm{~nm}$.

\subsection{Intracellular ROS Generation}

To measure the intracellular ROS levels in UVB-exposed HDFs, HDFs were seeded into 96-well plates at a density of $5 \times 10^{4}$ cell $/ \mathrm{mL}$ for $24 \mathrm{~h}$. Cells were then treated with licorice extracts $(100 \mu \mathrm{g} / \mathrm{mL})$ and UVB radiation $\left(100 \mathrm{~mJ} / \mathrm{cm}^{2}\right)$ for $24 \mathrm{~h}$. The cells were treated with $20 \mu \mathrm{M}$ of DCF-DA (Sigma) and incubated at $37^{\circ} \mathrm{C}$ for $20 \mathrm{~min}$. Intracellular ROS generation was measured using the microplate reader at excitation and emission wavelengths of 485 and $535 \mathrm{~nm}$, respectively.

\subsection{Protein Extraction}

HDFs were pretreated with licorice extracts $(100 \mu \mathrm{g} / \mathrm{mL})$ and UVB radiation $\left(100 \mathrm{~mJ} / \mathrm{cm}^{2}\right)$ for $24 \mathrm{~h}$. Whole fibroblast lysates were prepared in Radioimmunoprecipitation assay (RIPA) buffer (GenDEPOT, Katy, TX, USA) containing protease and phosphatase inhibitor cocktail (GenDEPOT). Cell lysates containing equal amounts of total protein, determined using the Bradford assay, were prepared following the manufacturer's instructions. The proteins were mixed with $4 \times$ sample buffer $(250 \mathrm{mM}$ Tris-HCl $6.8, \mathrm{SDS}, 40 \%$ glycerol, $8 \%$ 2-mercaptoethanol, $0.02 \%$ Bromophenol blue [GenDEPOT]), and boiled for $10 \mathrm{~min}$, following the manufacturer's instructions.

\subsection{Western Blot}

Western blotting was performed using $10 \%$ sodium dodecyl sulfate-polyacrylamide gel electrophoresis, followed by protein transfer to polyvinylidene fluoride membranes (0.45 $\mu \mathrm{m}$, Millipore, Darmstadt, Germany). The membrane was washed three times and blocked by soaking the membrane in TBS-T buffer ( $50 \mathrm{mM}$ Tris- $\mathrm{HCl}$ [pH 7.5], $150 \mathrm{mM} \mathrm{NaCl}$, and $0.1 \%$ Tween 20 ) containing $5 \%$ bovine serum albumin (GenDEPOT) for $30 \mathrm{~min}$. Then, the membrane was incubated with primary antibody (1:1000 dilution) overnight at $4{ }^{\circ} \mathrm{C}$, washed again three times, and treated with secondary antibody (1:2000 dilution) for $1 \mathrm{~h}$ at RT. All primary (mouse monoclonal $\beta$-actin, rabbit monoclonal COX-2, rabbit monoclonal iNOS, rabbit monoclonal NF- $\mathrm{kB}$ p65, and rabbit monoclonal NF- $\mathrm{kB}$ pp65) and secondary antibodies (anti-rabbit IgG, horseradish peroxidase (HRP)-linked antibody, anti-mouse IgG, HRP-linked antibody) were purchased from Abcam (Cambridge, UK) and Cell Signaling Technology (Beverly, MA, USA) [30]. Protein expression was visualized using an enhanced chemiluminescence reagent (Bio-Rad, Hercules, CA, USA), following the manufacturer's instructions. Quantitative analysis was conducted using the free software ImageJ (version 1.52a for Windows; NIH, Rockville, MD, USA).

\subsection{Reverse Transcription Polymerase Chain Reaction (RT-PCR)}

HDFs were pretreated with NL and HL extracts $(100 \mu \mathrm{g} / \mathrm{mL})$ for $24 \mathrm{~h}$ with UVB irradiation $\left(100 \mathrm{~mJ} / \mathrm{cm}^{2}\right)$. Total RNA was extracted with TRIzol reagent (Ambion, Austin, 
TX, USA), and $1 \mu \mathrm{g}$ was reverse transcribed into cDNA using the Reverse Transcriptase Premix Kit (Elpis Biotech, Daejeon, Korea) according to the manufacturer's instructions. RT-PCR was performed using Glyceraldehyde 3-phosphate dehydrogenase (GAPDH)-, IL-6-, and IL-1 $\beta$-specific primers (Bioneer, Daejeon, Korea). PCR to evaluate the expression of proinflammatory cytokines was performed using the Maxime PCR PreMix Kit (iNtRON Biotechnology, Seongnam, Korea), according to the manufacturer's instructions. Primers were designed using Primer-BLAST (NCBI, Bethesda, MD, USA). Table 1 shows the sequences of the primers used for RT-PCR. The PCR products were size fractionated by $1 \%$ agarose gel electrophoresis. After electrophoresis, the DNA bands were visualized using a UV transilluminator imaging system (Davinch-K, Seoul, Korea). Quantitative measurements were made using free ImageJ.

Table 1. Forward and reverse primer sequences for RT-PCR.

\begin{tabular}{ccc}
\hline Gene & \multicolumn{2}{c}{ Primer Sequence } \\
\hline \multirow{2}{*}{ IL-1 $\beta$} & $\mathrm{F}^{1}$ & GTATCACTCATTGTGGCTGTG \\
& $\mathrm{R}^{2}$ & ATTTTGTCGTTGCTTGGTTCTC \\
IL-6 & $\mathrm{F}$ & ATTACACATGTTCTCTGGGAAG \\
& $\mathrm{R}$ & TTTTACCTCTTGGTTGAAGATATG \\
GAPDH & $\mathrm{F}$ & AAAAGGGTCATCATCTCCGC \\
& $\mathrm{R}$ & CTTCTTGATGTCATCATACTTGG \\
\hline
\end{tabular}

${ }^{1} \mathrm{~F}$, forward; ${ }^{2} \mathrm{R}$, reverse; GAPDH, glyceraldehyde 3-phosphate dehydrogenase; IL, interleukin.

\subsection{Total Phenolic Content (TPC)}

TPC was determined using the Folin-Ciocâlteu method [31]. Each extract $(500 \mu \mathrm{L})$ was mixed with $1 \mathrm{~N}$ Folin-Ciocâlteu reagent (50 $\mu \mathrm{L}$, Sigma) for $3 \mathrm{~min}$, after which $20 \%$ sodium carbonate solution $(100 \mu \mathrm{L})$ was added. After $1 \mathrm{~h}$, the absorbance was measured at $725 \mathrm{~nm}$ using the microplate reader. TPC was calculated from the calibration curve using gallic acid (GA, Sigma), and the results were expressed as GA equivalents ( $y=0.7615 x+0.0649)$.

\subsection{High-Performance Liquid Chromatography (HPLC) Analysis}

Isoliquiritigenin contents of HL extracts were analyzed by HPLC with a UV-visible detector (HPLC: 1200 series, Agilent Technologies, Santa Clara, CA, USA; column: YMCODS-AM, $250 \times 4.6 \mathrm{~mm}, 5 \mu \mathrm{m}$, YMC Inc., Wilmington, NC, USA). The mobile phase of the analytical system used $0.5 \%$ formic acid-acetonitrile (A) and $0.5 \%$ formic acid-water operating under the following gradient: $0-8 \mathrm{~min}(20-20 \% \mathrm{~A}), 8-30 \mathrm{~min}(20-38 \% \mathrm{~A}), 30-42 \mathrm{~min}$ $(38-50 \% \mathrm{~A}), 42-47 \mathrm{~min}(50-90 \% \mathrm{~A}), 47-53 \mathrm{~min}(90-90 \% \mathrm{~A}), 53-54 \mathrm{~min}(90-20 \% \mathrm{~A})$, and 54-60 $\mathrm{min}(20-20 \% \mathrm{~A})$. The flow rate, detection wavelength, and injection volume were set to $1.0 \mathrm{~mL} / \mathrm{min}, 280 \mathrm{~nm}$, and $10 \mu \mathrm{L}$, respectively.

\subsection{Statistical Analysis}

All experimental results are presented as the mean \pm standard deviation (SD) of three independent measurements. Statistical analysis was performed using one-way analysis of variance, followed by Tukey's multiple comparison test using Prism 5.02 (GraphPad Software, San Diego, CA, USA), in addition to Duncan's multiple range test using IBM SPSS, ver. 22.0 for Windows. $p$-values $<0.05$ were considered to indicate statistical significance.

\section{Results}

\subsection{Heat Treatment Improved Antioxidant Activities of Licorice Extracts}

Heat treatment caused an increase in antioxidants. DPPH radical scavenging assay showed that NL extract had the lowest antioxidant activity ( $\mathrm{IC}_{50}$ value: $770.3 \pm 42.3 \mu \mathrm{g} / \mathrm{mL}$ ), while HL-1 extract had significantly increased antioxidant activity and HL-2 extract had the highest antioxidant activity ( $\mathrm{IC}_{50}$ value: $455.0 \pm 36.5$ and $299.2 \pm 10.8 \mu \mathrm{g} / \mathrm{mL}$, respectively) (Table 2). ABTS + radical scavenging assay showed similar results; NL extract had the lowest antioxidant activity ( $\mathrm{IC}_{50}$ value: $63.2 \pm 0.8 \mu \mathrm{g} / \mathrm{mL}$ ), while HL-1 extract had significantly 
increased antioxidant activity, and HL-2 extract showed the highest antioxidant activity ( $\mathrm{IC}_{50}$ value: $60.5 \pm 1.0$ and $43.7 \pm 10.8 \mu \mathrm{g} / \mathrm{mL}$, respectively) (Table 2 ).

Table 2. Antioxidant activities of the licorice extracts.

\begin{tabular}{ccc}
\hline Samples & DPPH $\left(\mathrm{IC}_{\mathbf{5 0}}, \boldsymbol{\mu \mathrm { g } / \mathrm { mL } )}\right.$ & ABTS $+\left(\mathrm{IC}_{\mathbf{5 0}}, \boldsymbol{\mu g} / \mathrm{mL}\right)$ \\
\hline NL & $770.3 \pm 42.3^{\mathrm{a}}$ & $63.2 \pm 0.8^{\mathrm{a}}$ \\
HL-1 & $455.0 \pm 36.5^{\mathrm{b}}$ & $60.5 \pm 1.0^{\mathrm{b}}$ \\
HL-2 & $299.2 \pm 10.8^{\mathrm{c}}$ & $43.7 \pm 0.8^{\mathrm{c}}$ \\
\hline
\end{tabular}

All data are presented as the mean $\pm \mathrm{SD}(n=3)$. Different letters $\left({ }^{\mathrm{a}, \mathrm{b}, \mathrm{c}}\right)$ indicate significant differences among mean values $\left(p<0.05\right.$, Duncan's multiple range test). HL-1, heat-treated licorice $\left(120^{\circ} \mathrm{C}\right)$; HL-2, heat-treated licorice $\left(130^{\circ} \mathrm{C}\right)$; $\mathrm{NL}$, non-treated licorice.

\subsection{Heat Treatment Improved the UV Photoprotective Effect of Licorice Extract by Enhancing Antioxidant Properties}

MTS assay showed $>100 \% \mathrm{HDF}$ cell viability for extract treatments of up to $100 \mu \mathrm{g} / \mathrm{mL}$; however, treatments of $200 \mu \mathrm{g} / \mathrm{mL}$ for both NL and HL extracts showed toxic effects on HDFs (Figure 1). Therefore, subsequent experiments used extracts of $100 \mu \mathrm{g} / \mathrm{mL}$. Exposure to UVB leads to accelerated cellular ROS levels [32]. ROS levels were 5.2-fold higher in the UVB control cells than in the non-treated control $(p<0.001)$ and 1.9-fold lower in the NL extract $(100 \mu \mathrm{g} / \mathrm{mL})$-treated samples than in the UVB control $(p<0.001)$ (Figure 2). HL-1 and HL-2 extract $(100 \mu \mathrm{g} / \mathrm{mL})$ treatments showed better inhibitory activities (2.3-fold and 3.8-fold, respectively, vs. UVB control, $p<0.001$ ) (Figure 2), indicating that heat treatment enhanced the antioxidant properties of licorice extract.

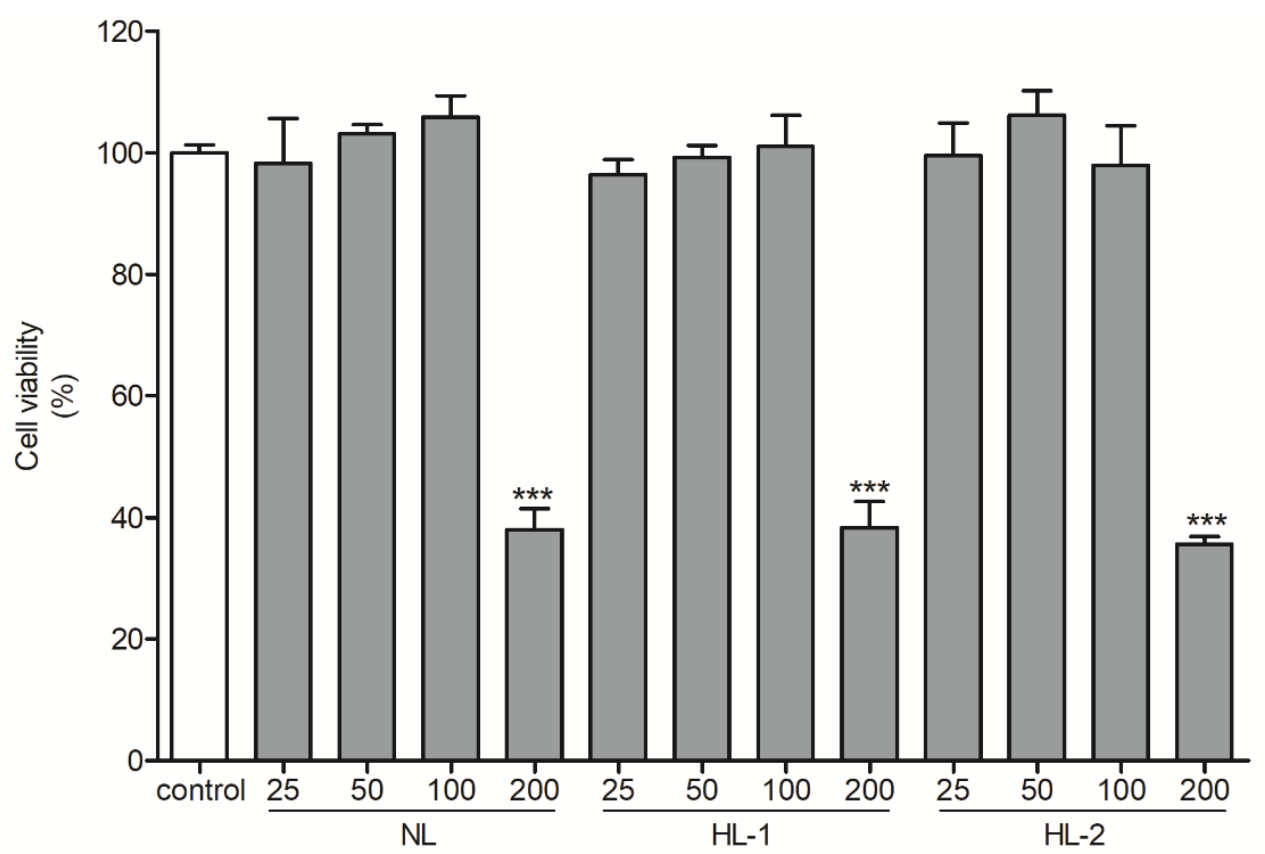

Figure 1. Viability of human dermal fibroblasts following treatment with heat-treated licorice extracts (25-200 $\mu \mathrm{g} / \mathrm{mL}$ ) for $24 \mathrm{~h}$. Cell viability was evaluated by MTS assay. The results are shown as the mean $\pm \mathrm{SD}(n=3) .{ }^{* * *} p<0.001$ vs. non-treated control. HL-1, heat-treated licorice $\left(120^{\circ} \mathrm{C}\right) ; \mathrm{HL}-2$, heat-treated licorice $\left(130^{\circ} \mathrm{C}\right)$; $\mathrm{NL}$, non-treated licorice. 


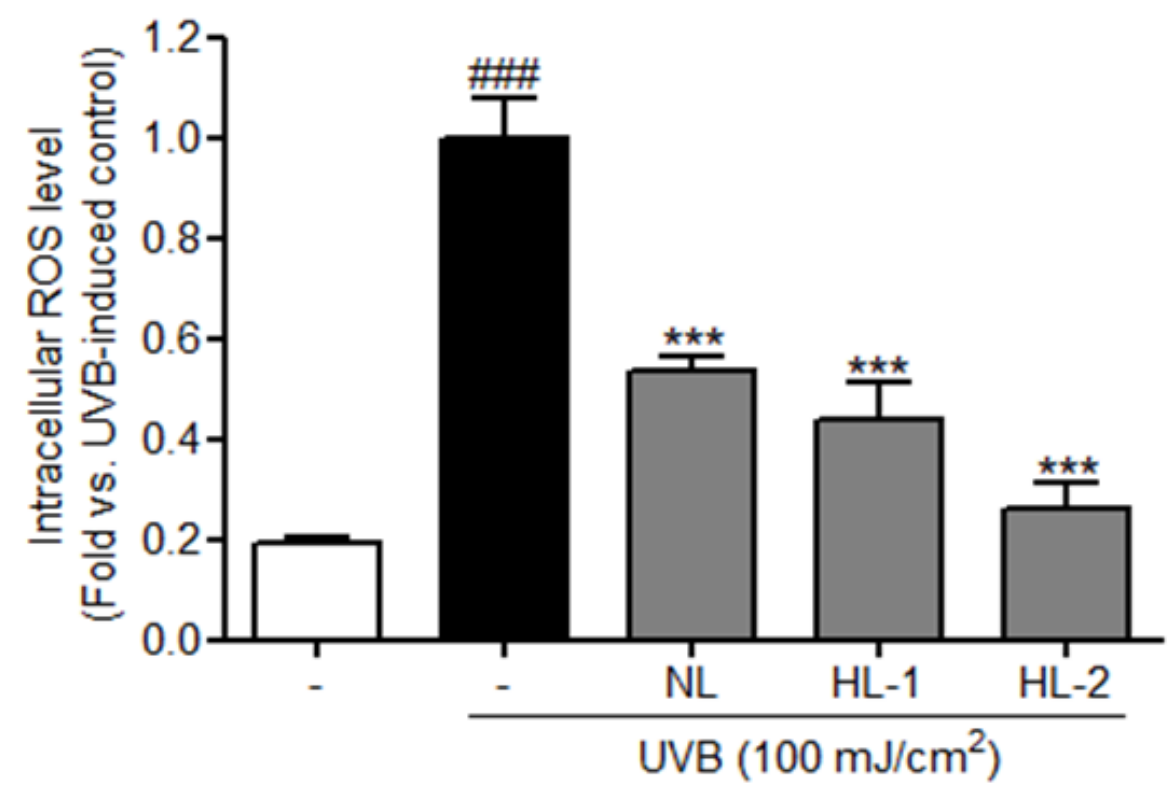

Figure 2. Intracellular ROS levels in UVB-exposed HDFs treated with $100 \mu \mathrm{g} / \mathrm{mL}$ licorice extracts for $24 \mathrm{~h}$, followed by DCF-DA $(20 \mu \mathrm{M})$ treatment for $20 \mathrm{~min}$. Intracellular ROS levels were measured using fluorescent confocal microscopy. Results are shown as the mean $\pm \operatorname{SD}(n=3) .{ }^{* * *} p<0.001$ vs. UVB-exposed control; \#\#\# $p<0.001$ vs. non-treated control. DCF-DA, $2^{\prime}, 7^{\prime}$-dichlorofluorescin diacetate; HDFs, human dermal fibroblasts; HL-1, heat-treated licorice $\left(120^{\circ} \mathrm{C}\right)$; HL-2, heat-treated licorice $\left(130^{\circ} \mathrm{C}\right)$; NL, non-treated licorice; UVB, ultraviolet $\mathrm{B}$.

\subsection{Heat Treatment Improved the UV Photoprotective Effect of Licorice Extract by Enhancing Anti-Inflammatory Properties}

The NF- $\mathrm{kB}$ subunit, NF- $\mathrm{kB}$ p65, upregulates inflammation-related signals and is induced by increased ROS accumulation [33]. Additionally, the production of proinflammatory cytokines, such as IL- 6 and IL- $1 \beta$, and inflammatory mediators, such as iNOS and COX-2, is induced by activated NF-KB $[34,35]$. We found that expression levels of inflammation-related factors, such as NF- $\mathrm{KB}$ p65, COX-2, and iNOS, were significantly increased in the UVB control HDFs (NF-кB pp65/p65: 2.1-fold; COX-2: 1.6-fold; iNOS: 2.0-fold vs. non-treated control, $p<0.001$ ) (Figure 3). Expression levels of p65, COX-2, and iNOS were reduced in cells treated with NL, HL-1, and HL-2 extracts. HL-2 extract showed the highest decrease in p65, COX-2, and iNOS levels (1.9- , 1.8-, and 2.3-fold, respectively, vs. UVB control, $p<0.001)$. Expression levels of IL-1 $\beta$ and IL-6 mRNAs were significantly increased in the UVB control (6.1- and 8.3-fold, respectively, vs. non-treated control, $p<0.001$ ) (Figure 4$)$. NL and HL-1 extracts $(100 \mu \mathrm{g} / \mathrm{mL})$ suppressed IL-1 $\beta$ and IL-6 mRNA levels (IL-1 $\beta$ : 2.7- and 3.4-fold, respectively, vs. UVB control, $p<0.001$; IL-6: $1.2-$ and 3.1-fold, respectively, vs. UVB control, $p<0.001)$. HL-2 extract $(100 \mu \mathrm{g} / \mathrm{mL})$ inhibited IL-1 $\beta$ and IL-6 mRNA levels the most (3.6- and 10.3-fold, respectively, vs. UVB control, $p$ $<0.001)$. Therefore, heat treatment enhanced the anti-inflammatory properties of licorice extract in HDFs. 


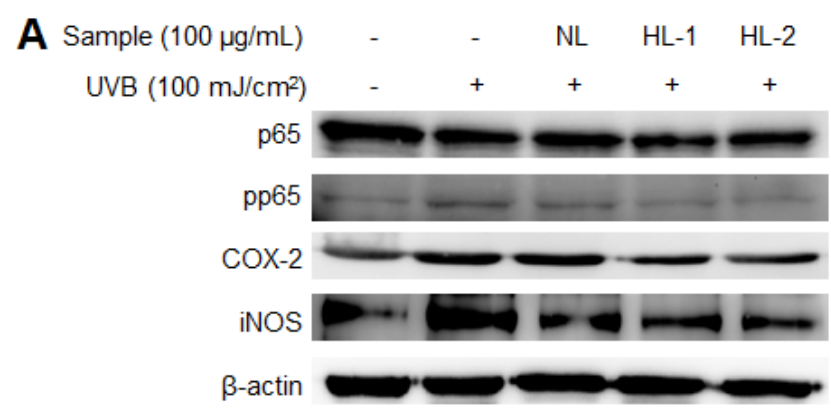

B

pp65/p65

cox-2

iNOS
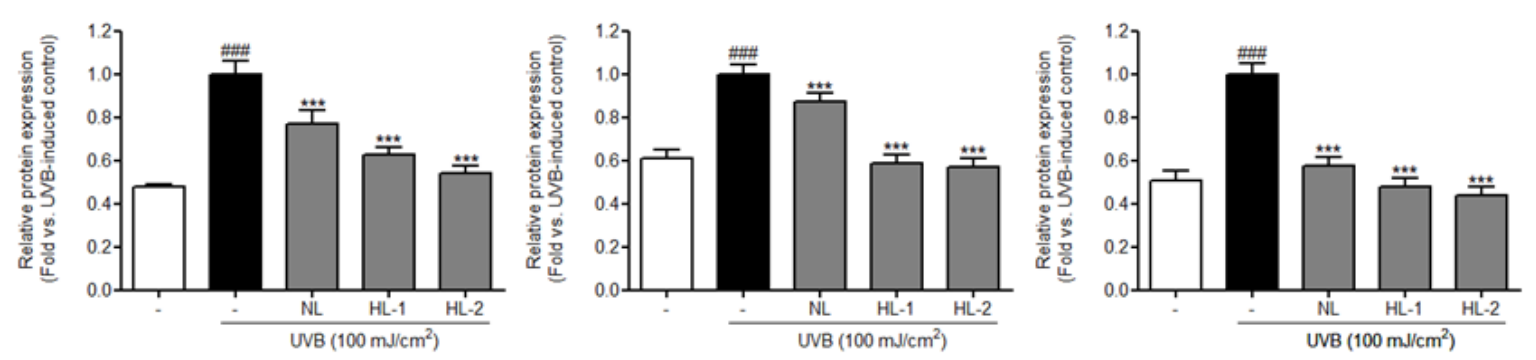

Figure 3. Effect of heat-treated-licorice extracts on the expression of NF- $\mathrm{kB}$ p65 and inflammation-related proteins in UVBexposed HDFs. Western blotting was performed to assess the expression levels of NF- $\mathrm{B}$ p $65, \mathrm{COX}-2$, and iNOS. The protein band intensities were normalized to that of $\beta$-actin and presented as the mean $\pm \operatorname{SD}(n=3) .{ }^{* * *} p<0.001$ vs. UVB-exposed control; \#\#\# $p<0.001$ vs. non-treated control. COX-2, cyclooxygenase-2; HDFs, human dermal fibroblasts; HL-1, heat-treated licorice $\left(120^{\circ} \mathrm{C}\right)$; HL-2, heat-treated licorice $\left(130^{\circ} \mathrm{C}\right)$; iNOS, inducible nitric oxide synthase; NL, non-treated licorice; NF- $\mathrm{kB}$; nuclear factor kappa B; UVB, ultraviolet B.

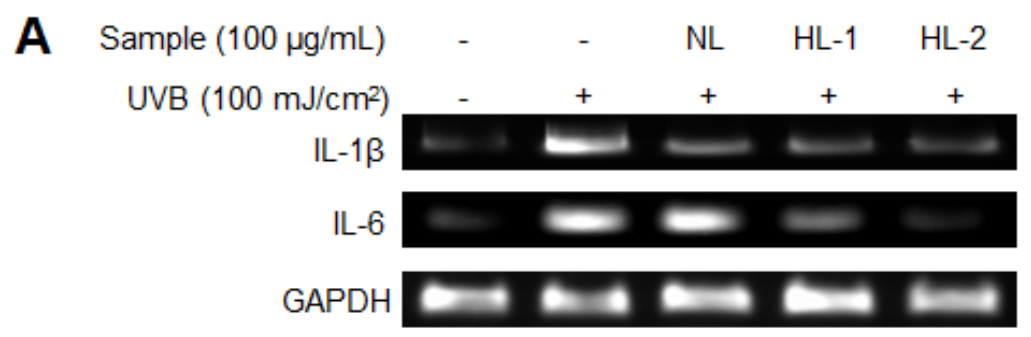

B

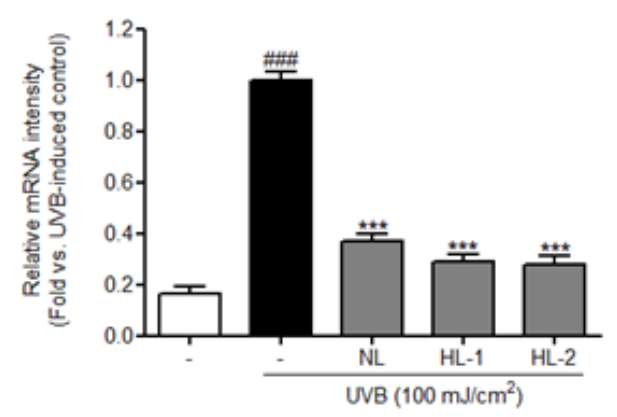

IL-6

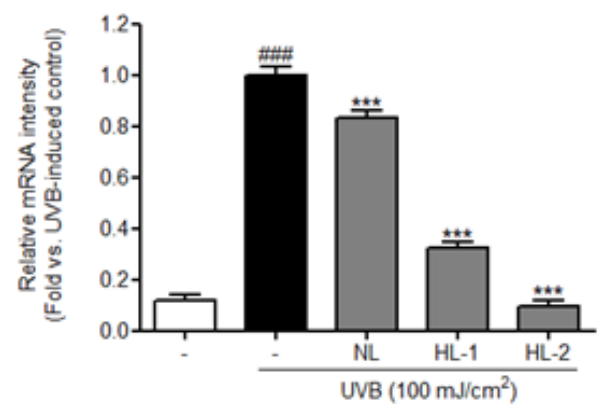

Figure 4. Effect of heat-treated-licorice extracts on proinflammatory mRNA cytokines in UVB-exposed HDFs. RT-PCR was performed to confirm the mRNA levels of IL-1 $\beta$ and IL-6. The mRNA band intensities were normalized to that of GAPDH and presented as the mean $\pm \mathrm{SD}(n=3)$. ${ }^{* * *} p<0.001$ vs. UVB-exposed control; \#\#\# $p<0.001$ vs. non-treated control. GAPDH, glyceraldehyde 3-phosphate dehydrogenase; HDFs, human dermal fibroblasts; HL-1, heat-treated licorice $\left(120^{\circ} \mathrm{C}\right) ; \mathrm{HL}-2$, heat-treated licorice $\left(130^{\circ} \mathrm{C}\right)$; IL, interleukin; NL, non-treated licorice; UVB, ultraviolet $\mathrm{B}$. 


\subsection{Heat Treatment Increased the Contents of Bioactive Compounds}

Heat treatment causes an increase in antioxidant components [36]. In this study, the antioxidant and anti-inflammatory activities of the HL extracts increased with heat treatment. The total contents of phenolics, which are responsible for the antioxidant activities of plants, and isoliquiritigenin, a phenolic compound with antioxidant and anti-inflammatory activities, were measured in licorice extracts to determine whether the components related to these activities improved with heat treatment. The HL-1 and HL-2 extracts had higher TPC (12.1 \pm 0.6 and $14.4 \pm 0.7 \mathrm{mg} \mathrm{GA} / \mathrm{g}$ extract, respectively) than NL extract (11.7 $\pm 0.7 \mathrm{mg} \mathrm{GA} / \mathrm{g}$ extract) (Table 3$)$. HPLC analysis showed higher isoliquiritigenin contents in HL-1 and HL-2 extracts $(2.82 \pm 0.14$ and $3.28 \pm 0.18 \mathrm{mg} / \mathrm{g}$ extract, respectively) than in NL extract $(2.40 \pm 0.24)$ (Figure 5). This indicates that heat treatment increased the phenolic contents of licorice extracts in proportion to the skinprotective effects of extracts. Therefore, phenolic compounds, especially isoliquiritigenin, likely play a crucial role in the UV photoprotective effects of licorice extracts.

A

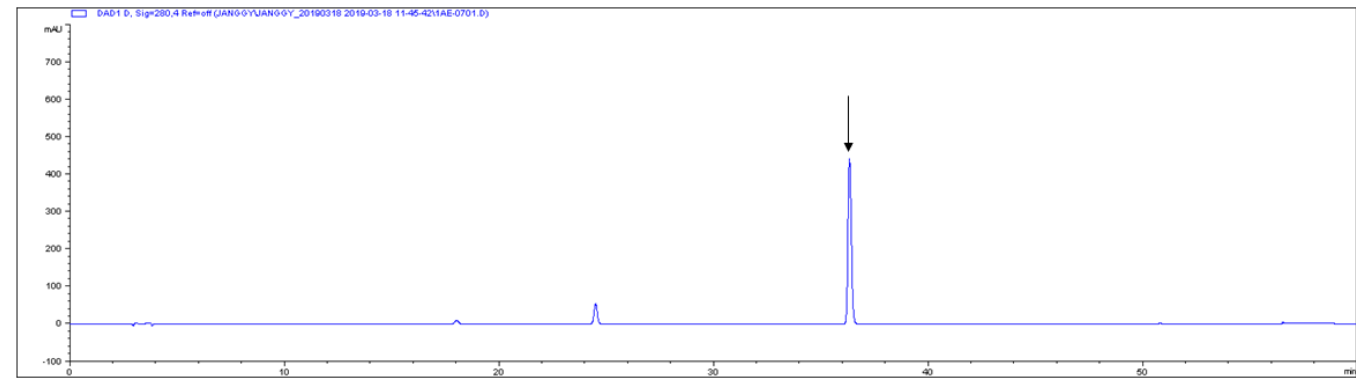

B

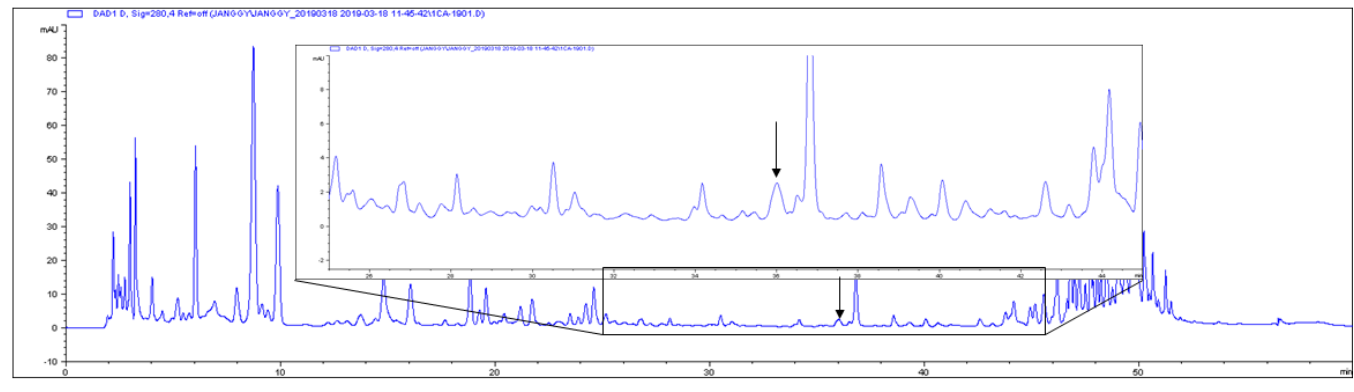

C

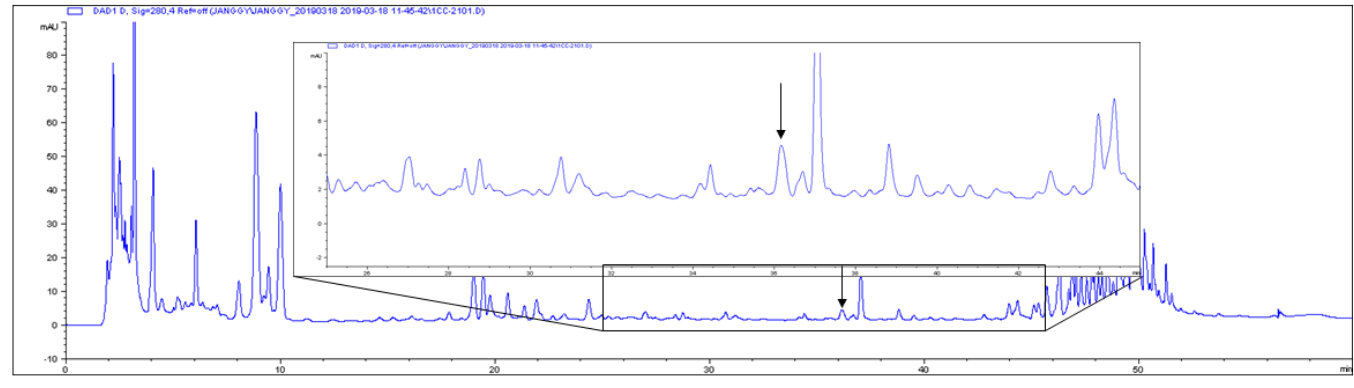

D

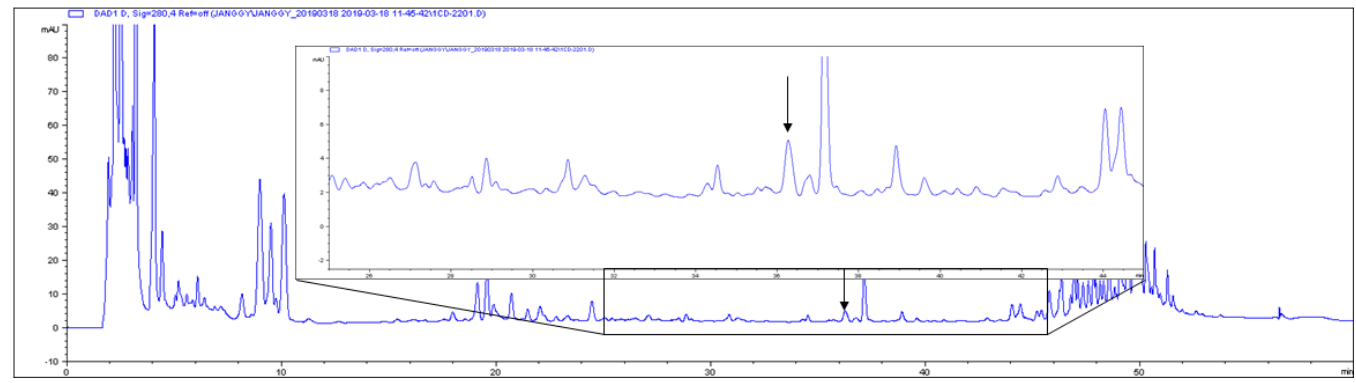

Figure 5. Typical chromatograms of isoliquiritigenin and licorice extracts based on HPLC analysis: (A) isoliquiritigenin standard, (B) non-treated licorice, (C) heat-treated licorice $\left(120^{\circ} \mathrm{C}\right)$, and (D) heat-treated licorice $\left(130{ }^{\circ} \mathrm{C}\right)$. HPLC, highperformance liquid chromatography. The arrow indicates the isoliquiritigenin peak (36,299 min). 
Table 3. Total phenolic and isoliquiritigenin content of licorice extracts.

\begin{tabular}{ccc}
\hline Samples & Total Phenolic Content $(\mathbf{m g ~ G A} / \mathbf{g}$ Extract) & Isoliquiritigenin $(\mathbf{m g} / \mathrm{g}$ Extract) \\
\hline NL & $11.7 \pm 0.7^{\mathrm{b}}$ & $2.40 \pm 0.24^{\mathrm{c}}$ \\
HL-1 & $12.1 \pm 0.6^{\mathrm{b}}$ & $2.82 \pm 0.14^{\mathrm{b}}$ \\
HL-2 & $14.4 \pm 0.6^{\mathrm{a}}$ & $3.28 \pm 0.18^{\mathrm{a}}$ \\
\hline
\end{tabular}

All data are presented as the mean $\pm \mathrm{SD}(n=3)$. Different letters $(\mathrm{a}, \mathrm{b}, \mathrm{c})$ indicate that mean values significantly differ $\left(p<0.05\right.$, Duncan's multiple range test). HL-1, heat-treated licorice $\left(120^{\circ} \mathrm{C}\right)$; HL-2, heat-treated licorice $\left(130{ }^{\circ} \mathrm{C}\right)$; NL, non-treated licorice.

\section{Discussion}

This study compared the protective effects of NL and HL extracts on UVB-exposed HDFs. HL-1 and HL-2 extracts showed better antioxidant activity than NL extracts in DPPH and ABTS+ radical scavenging assays (Table 2). In addition, NL and HL extracts inhibited the expression of intracellular ROS, inflammation-related proteins, and proinflammatory cytokines in UVB-exposed HDFs. UV radiation directly induces photoaging and indirectly increases ROS production, thereby promoting inflammatory factors and causing skin cancer [4]. In addition, ROS promote the expression of p65, a subunit of NF- $\mathrm{KB}$, in the cytoplasm. Phosphorylated p65 moves into the nucleus and acts as a transcription factor for COX-2, iNOS, and inflammatory cytokines and regulates inflammatory responses [37]. Intracellular ROS levels were effectively reduced in UVB-exposed HDFs treated with NL and HL extracts, most significantly by HL-2 extract (Figure 2). The expression of NFKB p65 activated by ROS was also reduced by NL and HL extracts. HL-2 extract most strongly inhibited the activation of $\mathrm{p} 65$. By inhibiting ROS production and activation of NF- $\mathrm{kB}$ p 65 by UVB, inflammation-related factors such as COX-2, iNOS, IL-6, and IL-1 $\beta$ were reduced. The HL-2 extract had the greatest inhibitory effect on the expression of inflammation-related factors (Figures 3 and 4). We found that the UV photoprotective effects of the NL and HL extracts were due to their antioxidant and anti-inflammatory activities. Phenolics exhibit various antioxidant and anti-inflammatory health effects [38]. During heat treatment, antioxidant capacity is improved through chemical reactions such as the Maillard reaction [39]. Melanoidin, a brown polymer produced by the reaction between sugar and amino acids in the Maillard reaction, has high antioxidant activity due to its high radical-scavenging activity and ability to chelate metals [40]. HL-2 extract had higher TPC than NL and HL-1 extracts (Table 3). Isoliquiritigenin contents were higher in HL extracts than in NL extract, and highest in HL-2 extract. These results indicate that time and temperature play important roles in the changes in phenolic composition during heat treatment [41]. Isoliquiritigenin inhibits ROS production and the NF- $\mathrm{KB}$ pathway [5]. Increased isoliquiritigenin in HL extracts may have increased antioxidant activity and inhibited ROS generation and activation of NF- $\mathrm{kB}$ p65 in UVB-exposed HDFs [15,42,43], thereby suppressing the expression of COX-2, iNOS, and cytokines. Therefore, heat treatment can improve the UV photoprotective effects of licorice extract on HDFs by increasing the contents of phenolics, such as isoliquiritigenin, in licorice (Figure 6). HL-2 extract is a natural substance that may help to regulate inflammatory responses and act as a powerful antioxidant in dermal fibroblasts. 


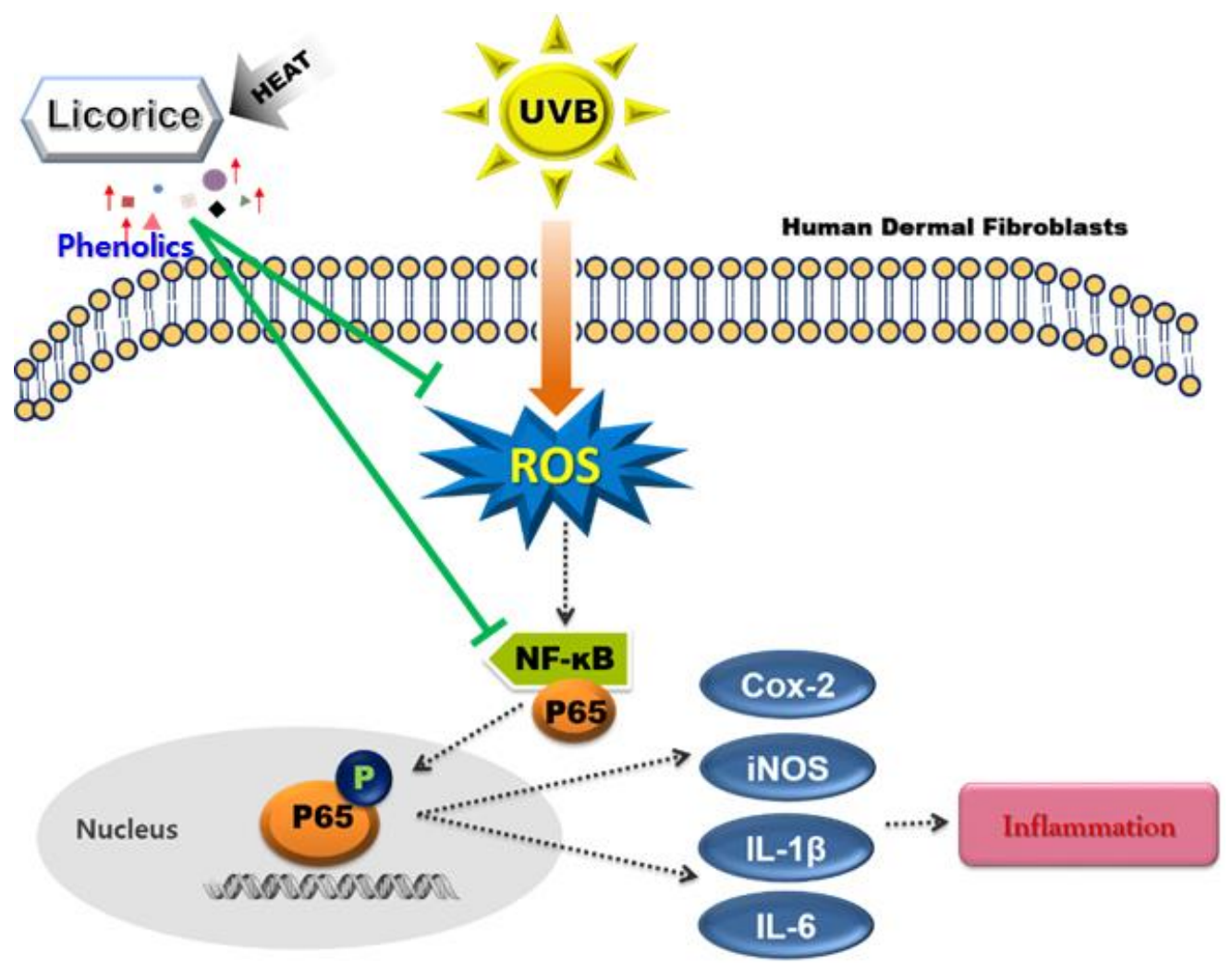

Figure 6. Schematic diagram of the UV photoprotective effects of licorice on HDFs. The green line and arrows indicate inhibition and stimulation, respectively. This schematic shows the potential protective effect of the HL extract against UVB-induced skin damage.

\section{Conclusions}

This study confirmed the effects of thermal processes on the UV photoprotective activity of licorice in dermal fibroblasts and determined the components related to this activity. The HL extracts had greater UV photoprotective effects, compared with the NL extract. The study showed that HL extracts can protect human dermal fibroblasts against UVB by suppressing intracellular ROS levels and the NF- $K B$ signaling pathway, and heat treatment can be used to improve the UV photoprotective effects of licorice extract on dermal fibroblasts by increasing the contents of bioactive compounds. The HL-2 extract has antioxidant and anti-inflammatory effects that may be useful in cosmetics to protect dermal fibroblasts against UVB.

Author Contributions: Conceptualization, G.Y.J. and H.D.K.; methodology, J.-Y.P., Y.-J.J., K.H.S., J.Y.L., G.-S.K. and M.H.K.; data curation, J.-Y.P., Y.-J.J., K.H.S., J.Y.L. and G.Y.J.; resources, J.H.L. and G.Y.J; writing—original draft preparation, J.-Y.P.; writing—review and editing, G.-S.K., G.Y.J. and H.D.K.; funding acquisition, G.Y.J. and H.D.K. All authors have read and agreed to the published version of the manuscript.

Funding: This work was carried out with the support of "Cooperative Research Program for Agriculture Science and Technology Development (Project No. PJ01273002)" and the RDA Fellowship Program of National Institute of Horticultural and Herbal Science, Rural Development Administration, Republic of Korea.

Conflicts of Interest: The authors declare no conflict of interest. The funding sponsors had no role in the design of the study; collection, analyses, or interpretation of the data; writing of the manuscript; or the decision to publish the results. 


\section{References}

1. Schuch, A.P.; Moreno, N.C.; Schuch, N.J.; Menck, C.F.M.; Garcia, C.C.M. Sunlight damage to cellular DNA: Focus on oxidatively generated lesions. Free Radic. Biol. Med. 2017, 107, 110-124. [CrossRef] [PubMed]

2. Song, J.; Smart, R.; Wang, H.; Dambergs, B.; Sparrow, A.; Qian, M.C. Effect of grape bunch sunlight exposure and UV radiation on phenolics and volatile composition of Vitis vinifera L. cv. Pinot noir wine. Food Chem. 2015, 173, 424-431. [CrossRef] [PubMed]

3. Barnes, P.W.; Williamson, C.E.; Lucas, R.M.; Robinson, S.A.; Madronich, S.; Paul, N.D.; Bornman, J.F.; Bais, A.F.; Sulzberger, B.; Wilson, S.R. Ozone depletion, ultraviolet radiation, climate change and prospects for a sustainable future. Nat. Sustain. 2019, 2 569-579. [CrossRef]

4. Jung, Y.R.; Kim, D.H.; Kim, S.R.; An, H.J.; Lee, E.K.; Tanaka, T.; Kim, N.D.; Yokozawa, T.; Park, J.N.; Chung, H.Y. Anti-wrinkle effect of magnesium lithospermate B from Salvia miltiorrhiza BUNGE: Inhibition of MMPs via NF-kB signaling. PLoS ONE 2014, 9, e102689. [CrossRef] [PubMed]

5. Ribeiro, F.M.; Ratti, B.A.; dos Santos Rando, F.; Fernandez, M.A.; Ueda-Nakamura, T.; Lautenschlager, S.d.O.S.; Nakamura, C.V. Metformin effect on driving cell survival pathway through inhibition of UVB-induced ROS formation in human keratinocytes. Mech. Ageing Dev. 2020, 192, 111387. [CrossRef]

6. Gao, Y.; Lv, X.; Yang, H.; Peng, L.; Ci, X. Isoliquiritigenin exerts antioxidative and anti-inflammatory effects via activating the KEAP-1/Nrf2 pathway and inhibiting the NF-KB and NLRP3 pathways in carrageenan-induced pleurisy. Food Funct. 2020, 11, 2522-2534. [CrossRef]

7. Kim, H.D.; Park, J.Y.; Noh, H.J.; Lee, S.E.; Lee, J.H.; Seo, K.H. Anti-inflammatory activity of Ganoderma lucidum by inhibition of NF-kB p65 phosphorylation. Korean J. Agric. Sci. 2019, 46, 653-660.

8. Liu, Y.Y.; Yang, Y.N.; Feng, Z.M.; Jiang, J.S.; Zhang, P.C. Eight new triterpenoid saponins with antioxidant activity from the roots of Glycyrrhiza uralensis Fisch. Fitoterapia 2019, 133, 186-192. [CrossRef]

9. Varsha, S.; Agrawal, R.; Sonam, P. Phytochemical screening and determination of anti-bacterial and anti-oxidant potential of Glycyrrhiza glabra root extracts. J. Environ. Res. Dev. 2013, 7, 4A.

10. Conidi, C.; Fucà, L.; Drioli, E.; Cassano, A. A membrane-based process for the recovery of glycyrrhizin and phenolic compounds from licorice wastewaters. Molecules 2019, 24, 2279. [CrossRef]

11. Martins, N.; Barros, L.; Duenas, M.; Santos Buelga, C.; Ferreira, I.C. Characterization of phenolic compounds and antioxidant properties of Glycyrrhiza glabra L. rhizomes and roots. RSC Adv. 2015, 5, 26991-26997. [CrossRef]

12. Ji, S.; Li, Z.; Song, W.; Wang, Y.; Liang, W.; Li, K.; Tang, S.; Wang, Q.; Qiao, X.; Zhou, D. Bioactive constituents of Glycyrrhiza uralensis (licorice): Discovery of the effective components of a traditional herbal medicine. J. Nat. Prod. 2016, 79, 281-292. [CrossRef]

13. Xuan, S.H.; Park, Y.M.; Ha, J.H.; Jeong, Y.J.; Park, S.N. The effect of dehydroglyasperin C on UVB-mediated MMPs expression in human HaCaT cells. Pharmacol. Rep. 2017. [CrossRef]

14. Hamad, G.M.; Abd Elaziz, A.I.; Hassan, S.A.; Shalaby, M.A.; azim Mohdaly, A.A.A. Chemical Composition, Antioxidant, Antimicrobial and Anticancer Activities of Licorice (Glycyrrhiza glabra L.) Root and Its Application in Functional Yoghurt. Food Nutr. Res. 2020, 8, 707-715. [CrossRef]

15. Vlaisavljević, S.; Šibul, F.; Sinka, I.; Zupko, I.; Ocsovszki, I.; Jovanović Šanta, S. Chemical composition, antioxidant and anticancer activity of licorice from Fruska Gora locality. IND 2018, 112, 217-224. [CrossRef]

16. Yu, D.; Liu, X.; Zhang, G.; Ming, Z.; Wang, T. Isoliquiritigenin inhibits cigarette smoke-induced COPD by attenuating inflammation and oxidative stress via the regulation of the Nrf2 and NF-kB signaling pathways. Front. Pharmacol. 2018, 9, 1001. [CrossRef]

17. Tang, Y.; Wang, C.; Wang, Y.; Zhang, J.; Wang, F.; Li, L.; Meng, X.; Li, G.; Li, Y.; Wang, L. Isoliquiritigenin attenuates LPS-induced AKI by suppression of inflammation involving NF-кB pathway. Am. J. Transl. Res. 2018, 10, 4141.

18. Hou, C.; Li, W.; Li, Z.; Gao, J.; Chen, Z.; Zhao, X.; Yang, Y.; Zhang, X.; Song, Y. Synthetic isoliquiritigenin inhibits human tongue squamous carcinoma cells through its antioxidant mechanism. Oxid. Med. Cell. Longev. 2017, 2017, 1379430. [CrossRef]

19. Sung, M.W.; Li, P.C. Chemical analysis of raw, dry-roasted, and honey-roasted licorice by capillary electrophoresis. ELP 2004, 25, 3434-3440. [CrossRef]

20. Ota, M.; Xu, F.; Li, Y.L.; Shang, M.Y.; Makino, T.; Cai, S.Q. Comparison of chemical constituents among licorice, roasted licorice, and roasted licorice with honey. J. Nat. Med. 2018, 72, 80-95. [CrossRef]

21. Lee, S.K.; Park, K.K.; Park, J.H.Y.; Lim, S.S.; Chung, W.Y. The inhibitory effect of roasted licorice extract on human metastatic breast cancer cell-induced bone destruction. Phytother. Res. 2013, 27, 1776-1783. [CrossRef]

22. Maghsoudlou, Y.; Ghajari, M.A.; Tavasoli, S. Effects of heat treatment on the phenolic compounds and antioxidant capacity of quince fruit and its tisane's sensory properties. J. Food Sci. Technol. 2019, 56, 2365-2372. [CrossRef]

23. Hwang, I.G.; Kim, H.Y.; Park, B.R.; Han, H.M.; Yoo, S.M. Effect of heat treatment on the antioxidant properties of yacon (Smallanthus sonchifolius). Korean J. Food Nutr. 2013, 26, 857-864. [CrossRef]

24. Wu, H.-Y.; Yang, K.-M.; Chiang, P.-Y. Roselle anthocyanins: Antioxidant properties and stability to heat and pH. Molecules 2018, 23, 1357. [CrossRef]

25. Madihah, K.K.; Zaibunnisa, A.; Norashikin, S.; Rozita, O.; Misnawi, J. Optimization of roasting conditions for high-quality Arabica coffee. Int. Food Res. J. 2013, 20, 1623.

26. Vodnar, D.C.; Călinoiu, L.F.; Dulf, F.V.; Ştefănescu, B.E.; Crişan, G.; Socaciu, C. Identification of the bioactive compounds and antioxidant, antimutagenic and antimicrobial activities of thermally processed agro-industrial waste. Food Chem. 2017, 231, 131-140. [CrossRef] 
27. Călinoiu, L.F.; Vodnar, D.C. Thermal processing for the release of phenolic compounds from wheat and oat bran. Biomolecules 2020, 10, 21. [CrossRef]

28. Mishra, K.; Ojha, H.; Chaudhury, N.K. Estimation of antiradical properties of antioxidants using DPPH assay: A critical review and results. Food Chem. 2012, 130, 1036-1043. [CrossRef]

29. Lee, J.Y.; Park, J.Y.; Seo, H.T.; Seong, H.A.; Ji, Y.J.; Lee, S.E.; Seo, K.H.; Kim, H.D. Samnamul (Shoots of Aruncus dioicus) Inhibit Adipogenesis by Downregulating Adipocyte-Specific Transcription Factors in 3T3-L1 Adipocytes. Processes 2020, 8, 1576. [CrossRef]

30. Mahmood, T.; Yang, P.C. Western blot: Technique, theory, and trouble shooting. N. Am. J. Med. Sci. $2012,4,429$.

31. Fazio, A.; Plastina, P.; Meijerink, J.; Witkamp, R.F.; Gabriele, B. Comparative analyses of seeds of wild fruits of Rubus and Sambucus species from Southern Italy: Fatty acid composition of the oil, total phenolic content, antioxidant and anti-inflammatory properties of the methanolic extracts. Food Chem. 2013, 140, 817-824. [CrossRef] [PubMed]

32. Kong, Y.H.; Xu, S.P. Juglanin administration protects skin against UVB-induced injury by reducing Nrf2-dependent ROS generation. Int. J. Mol. Med. 2020, 46, 67-82. [CrossRef] [PubMed]

33. Subedi, L.; Lee, T.H.; Wahedi, H.M.; Baek, S.H.; Kim, S.Y. Resveratrol-enriched rice attenuates UVB-ROS-induced skin aging via downregulation of inflammatory cascades. Oxi. Med. Cell. Longev. 2017, 2017, 8379539. [CrossRef] [PubMed]

34. Kremer, J.L.; Melo, G.P.; Marinello, P.C.; Bordini, H.P.; Rossaneis, A.C.; Sábio, L.R.; Cecchini, R.; Cecchini, A.L.; Verri, W.A., Jr.; Luiz, R.C. Citral prevents UVB-induced skin carcinogenesis in hairless mice. J. Photochem. Photobiol. B 2019, 198, 111565. [CrossRef]

35. Tang, S.C.; Liao, P.Y.; Hung, S.J.; Ge, J.S.; Chen, S.M.; Lai, J.C.; Hsiao, Y.P.; Yang, J.H. Topical application of glycolic acid suppresses the UVB induced IL-6, IL-8, MCP-1 and COX-2 inflammation by modulating NF- $\mathrm{kB}$ signaling pathway in keratinocytes and mice skin. J. Dermatol. Sci. 2017, 86, 238-248. [CrossRef]

36. Aydogan-Coskun, B.; Coklar, H.; Akbuluta, M. Effect of heat treatment for liquefaction and pasteurization on antioxidant activity and phenolic compounds of Astragalus and sunflower-cornflower honeys. Food Sci. 2020, 40, 629-634. [CrossRef]

37. Seo, K.H.; Lee, J.Y.; Park, J.Y.; Jang, G.Y.; Kim, H.D.; Lee, Y.S.; Kim, D.H. Differences in anti-inflammatory effect of immature and mature of Rubus coreanus fruits on LPS-induced RAW 264.7 macrophages via NF-kB signal pathways. BMC Complement. Altern. Med. 2019, 19, 89. [CrossRef]

38. Kumar, N.; Gupta, S.; Chand Yadav, T.; Pruthi, V.; Kumar Varadwaj, P.; Goel, N. Extrapolation of phenolic compounds as multi-target agents against cancer and inflammation. DYN 2019, 37, 2355-2369. [CrossRef]

39. Hudson da Silva Souza, I.; Nogueira, J.P.; Rajan, M.; Santos Leite Neta, M.T.; Narain, N. Babassu Oil (Orbynia phalerata), an Artisanal Product: Process Optimization of Seed Roasting on Yield, Phenolic Compounds, and Antioxidant Capacity. Eur. J. Lipid Sci. Technol. 2021, 123, 2000163. [CrossRef]

40. Starowicz, M.; Ostaszyk, A.; Zielinski, H. The relationship between the browning index, total phenolics, color, and antioxidant activity of polish-originated honey samples. Foods 2021, 10, 967. [CrossRef]

41. Xu, G.H.; Ye, X.Q.; Chen, J.C.; Liu, D.H. Effect of heat treatment on the phenolic compounds and antioxidant capacity of citrus peel extract. J. Agric. Food Chem. 2007, 55, 330-335. [CrossRef]

42. Ji, B.; Guo, W.; Ma, H.; Xu, B.; Mu, W.; Zhang, Z.; Amat, A.; Cao, L. Isoliquiritigenin suppresses IL-1 $\beta$ induced apoptosis and inflammation in chondrocyte-like ATDC5 cells by inhibiting NF- $\mathrm{kB}$ and exerts chondroprotective effects on a mouse model of anterior cruciate ligament transection. Int. J. Mol. Med. 2017, 40, 1709-1718. [CrossRef]

43. Ye, H.; Yang, X.; Chen, X.; Shen, L.; Le, R. Isoliquiritigenin protects against angiotensin II-induced fibrogenesis by inhibiting NF-кB/PPAR $\gamma$ inflammatory pathway in human Tenon's capsule fibroblasts. Exp. Eye. Res. 2020, 199, 108146. [CrossRef] 